\title{
HISTORIA DEL PIRAGÜISMO OLÍMPICO ESPAÑOL: LA TRAYECTORIA DEPORTIVA DE HERMINIO MENÉNDEZ RODRÍGUEZ
}

\author{
Agustín Antuña Suárez \\ Academia Olímpica Española \\ Fecha de recepción: Febrero de 2015 \\ Fecha de aceptación: Junio de 2015 \\ http://dx.doi.org/10.15366/citius2015.8.2.002
}

\section{Resumen:}

El piragüismo español empezó a destacar a nivel internacional en la década de los setenta. El presente trabajo supone, a través de la trayectoria del deportista asturiano Herminio Menéndez Rodríguez, un rescate de las circunstancias de la génesis de este deporte en España y un acercamiento a los triunfos y las especiales circunstancias de la historia olímpica del piragüismo español. Él supuso el hito de la participación en cuatro ediciones de los Juegos Olímpicos: Múnich, 1972, Montreal, 1976, Moscú, 1980 y los Ángeles, 1984. Sus triunfos en dichos juegos y su exitosa trayectoria deportiva son aquí rescatados a fin de llevar a cabo un recuerdo que pretende ser también un pequeño homenaje a este gran deportista olímpico español.

Palabras clave: Herminio Menéndez Rodríguez, Piragüismo, Juegos Olímpicos, Historia del Olimpismo español, Medallistas olímpicos españoles.

\section{SPANISH OLYMPIC KAYAKING HISTORY: HERMINIO MENÉNDEZ RODRÍGUEZ}

\begin{abstract}
:
Spanish kayaking began to stand out at an international level in the 1970s. This research involves, through the career of the Asturian sportsman Herminio Menéndez Rodríguez, a collection of circumstances of the origin of this sport in Spain, and an approach to the triumphs and the special circumstances of the history of Spanish Olympic kayaking. He achieved the milestone of participation in five editions of the Olympic Games: Munich 1972, Montreal 1976, Moscow 1980 and Los Angeles, 1984. His triumphs in these games and his successful sporting career are collected here to carry out a memory that also aims to be a tribute to this great Spanish Olympian.
\end{abstract}

Keywords: Herminio Menéndez Rodríguez, Kayaking, Olympics Games, 


\section{Introducción}

Herminio Menéndez Rodríguez es uno de los más importantes deportistas españoles en el ámbito olímpico. No sólo participó en cuatro ediciones consecutivas de los Juegos: Múnich 72, Montreal 76, Moscú 80 y Los Ángeles 84, sino que también consiguió tres medallas en su participación en Juegos Olímpicos. Cuando Herminio obtuvo su tercera medalla, en esos momentos, se convirtió en el deportista olímpico español que más medallas había logrado. Este hito como deportista es un hecho a destacar que Menéndez enarbolaba cuando decidió su retirada tras su asistencia a la edición de Los Ángeles en 1984.

La revisión de su trayectoria histórica como deportista nos lleva a calificarle como el más grande campeón de piragüismo que ha dado nuestro país. Sus éxitos olímpicos y los logros conseguidos en un largo y fructífero recorrido, cuantitativa y cualitativamente hablando, nos llevan a reconocerle como una figura legendaria del deporte español, que forma parte de una historia reciente de gran interés para ser recordada.

\section{Los inicios}

Herminio Menéndez Rodríguez vino a este mundo en Asturias, en la villa marinera de Candás el 20 de diciembre de 1953.

Sus primeros años transcurrieron, como la mayoría de los niños de aquellos años, jugando por los alrededores del muelle candasín y dándole patadas a la pelota en la playa. El fútbol fue, precisamente, el primer deporte por el que sintió afición. Comenzó a jugar muy pronto en el equipo del Candás juvenil, en el que se destacó por sus excelentes maneras como centrocampista.

Cuando contaba trece años, Amando Prendes, que acababa de fundar un club de piragüismo, que se denominó Los Gorilas, y que estaba todo el día a la caza de talentos deportivos, logró convencer al entones joven futbolista para que probase fortuna con la piragua, en la cual ya se habían iniciado algunos de sus amigos. Comenzó, un poco por conocer una nueva experiencia, a dar sus primeras paladas en el muelle de Candás, sobre las inquietas aguas del Cantábrico.

Transcurrido un año, ya contando catorce, participó en el Campeonato de Asturias de Piragua-cross y se proclamó campeón de su categoría, la infantil. Era su primer triunfo. Esta gran alegría, le sirvió de estímulo para decidir seguir con la piragua, aunque sin abandonar todavía el futbol.

Dos años más tarde obtuvo con su club, Los Gorilas, el primer éxito importante, al proclamarse campeones de España de Piragua-cross, en Madrid. Era 
el primer triunfo a escala nacional del club de Candás y Herminio saboreaba las mieles de los primeros galardones. Aquel éxito le predispuso decisivamente sobre la idea de que su futuro deportivo no estaba en el fútbol, sino en el piragüismo.

$\mathrm{Al}$ año siguiente la Federación Española realizó un control, en categoría juvenil, para el equipo nacional, que se llevó a cabo en el pantano de Trasona. Herminio, para entonces, aunque acababa de comenzar a trabajar en la factoría de ENSIDESA, definitivamente, ya estaba resuelto en su disposición para continuar su dedicación al deporte de la piragua y, a pesar de sus turnos laborales, y el esfuerzo importante que su preparación le suponía, cada día se esforzaba con empeño en sus entrenamientos ante la gran ilusión que le suponía poder conseguir una plaza en la selección juvenil. Su sacrificio obtuvo la compensación de verse incluido en el equipo nacional que participó en el Campeonato del Mundo Juvenil, que se celebró en Rumania. Aquello era un sueño para el chaval de Candas.

\section{La participación en su primer Campeonato del Mundo}

Todos los seleccionados se concentraron en Rumanía y allí comenzó una nueva etapa para el piragüismo español. Este primer contacto con los rumanos y el del año siguiente fueron decisivos para elevar el nivel técnico de los palistas españoles. Herminio comenzó a progresar de forma extraordinaria. Cuando salieron de España su posición en el ranquin de nuestro país estaba entre el cuarto o quinto lugar de la categoría juvenil. Después en Rumanía consiguió que sus marcas superaran a las de sus compañeros y, al término de la concentración, que duró un mes, estaba a la cabeza de los juveniles. Era el año 1971.

Debutó en su primer Campeonato del Mundo, (del total de diez en que tomó parte a lo largo de su vida deportiva) obteniendo la sexta plaza en el K-4. Además Herminio consiguió llegar a las finales en K-1, siendo el primer juvenil en la historia del piragüismo español que alcanzaba esta meta. Tenía entonces diecisiete años. El seleccionador español, Eduardo Herrero, a la vista de su progresión y sus marcas, le incluyó en el equipo nacional sénior, y como consecuencia participó también en el Mundial sénior de Rumanía, formando parte del K-4 en 1.000 metros. Comenzaba a gestarse un cuarteto español que, con algunos retoques, alcanzaría, años más tarde, los primeros lugares del piragüismo internacional. A partir de aquel momento Herminio quedó definitivamente encuadrado en el equipo nacional, en el que continuó hasta finales de 1984, a la vuelta de los Juegos Olímpicos de Los Ángeles. En este largo periodo, el piragüismo español escribió las más importantes páginas de su historia y en ellas, como protagonista central, estuvo siempre este candasín universal Herminio Menéndez. 


\section{Rumanía: La verdad descarnada}

Los rectores deportivos españoles habían quedado muy satisfechos de los resultados conseguidos en Rumanía y suscribieron un compromiso con el equipo rumano, de cara a los Juegos Olímpicos de Múnich de 1972. A principios de dicho año, fue invitado a España el equipo rumano, y se organizó una concentración conjunta con el equipo español en Sevilla. Durante dos meses, desarrollaron un intenso trabajo conjunto, a fin de mejorar e impulsar una mejora sustancial en las técnicas que en aquellos años se conocían y que podían implicar un incremento del rendimiento del equipo español. De entre los mejores deportistas que participaron en aquella concentración sevillana, se pretendía hacer la selección del grupo que, en el mes de abril, debía trasladarse a Rumania, donde deberían permanecer hasta la celebración de los Juegos Olímpicos, es decir, más de cuatro meses. Era, por tanto, la concentración más prolongada, más dura y el intento deportivo más serio realizado hasta entonces por un equipo español.

A Rumanía llegaron un total de veintiún deportistas, de los cuales al final solamente podrían quedar siete. Veintiún jóvenes que aspiraban a quedar entre los elegidos. Unos habían abandonado los estudios. Otros, el trabajo. Todos, por supuesto, su familia, amigos, entorno. Su máxima ilusión era estar entre aquellos que tendrían el gran honor de ser olímpicos. Todos soñaban con la gloria. Desgraciadamente, solo una tercera parte podrían conseguirlo. El resto deberían regresar a sus hogares cabizbajos, silenciosos, tal vez frustrados para siempre. Era la otra cara del deporte.

De los recuerdos de Herminio Rodríguez rescatamos algunas circunstancias de la evolución del ambiente que se fue viviendo. Como es lógico, lo que en un principio era una piña de jóvenes alegres, amigos, optimistas, solidarios, ... el grupo se fue convirtiendo poco a poco en un colectivo en el que existían diferencias, silencios, roces, desconfianzas. La culpa era de aquellos segundos, aquellas décimas que el cronómetro, juez rígido e implacable, iba marcando día a día. La elección era definitiva e inflexible. El crono sería el único en dictar sentencia. Un catarro, un enfriamiento, una lesión, cualquier contratiempo que repercutiese negativamente en el rendimiento, podía ser la causa suficiente para quedar fuera. Y fueron pasando los días, las semanas, los meses y de forma regular fueron regresando a sus hogares aquellos, al principio, animosos muchachos, que un día muy cercano soñaron con la fama. Unos volvieron al no cumplir con las marcas exigidas. Otros no esperaron tanto. La tensión de aquel ambiente era tan fuerte que algunos no lo pudieron soportar. Finalmente, quedaron los siete elegidos, los que al final demostraron ser los mejores y, entre ellos, dos asturianos: Ramón Menéndez Palmeiro, otro miembro del club de piragüismo Los Gorilas, y Herminio Menéndez. 


\section{Los Juegos de Múnich de 1972: El Debut Olímpico}

Los Juegos Olímpicos de Múnich, fueron famosos por muchas razones entre otras por una organización excelente. Aquella edición de los Juegos fue testigo del arranque del piragüismo español a niveles internacionales, así como del bautismo olímpico de este deportista asturiano candasín. Aquel K-4 que, tímidamente, había debutado en el Mundial de Rumanía, estuvo integrado en aquella ocasión por Herminio, Celorrio, Álvaro y Sanz. De ellos, Herminio y Celorrio fueron designados para formar el K-2. Ambos tenían entonces dieciocho años y formaban la pareja más joven de los Juegos.

Consiguieron llegar a semifinales y no pudieron pasar a las finales por una décima de segundo. Herminio reflexionaba y recordaba la circunstancia, de que allí comprendió el valor de las décimas de segundo y lo que significaba llegar varias embarcaciones en un pañuelo y tener que esperar a conocer la clasificación, al no poder determinarlo por ellos mismos. A pesar de no entrar en finales, los rectores deportivos españoles se dieron cuenta que allí se encontraba un futuro gran equipo que, de continuar en la misma línea de superación, podrían alcanzar magníficos resultados en los próximos años. Hoy podemos afirmar que no se equivocaron.

\section{Nuevas incorporaciones y campeonatos mundiales}

Al año siguiente se produjo la incorporación de otros dos deportistas que fueron fundamentales para formar el equipo de K-4 español de los próximos años: José Díaz-Flor y Ramón Misione. Los Mundiales de aquel año tuvieron lugar en Tampere (Finlandia). En el K-2 de 10.000 metros, Herminio y Celorrio llegaron a las finales, ocupando la séptima plaza. Las diferencias entre los resultados de los participantes españoles y las conseguidas por los más destacados equipos internacionales se empezaron a mostrar mínimas y los campeones extranjeros comenzaron a inquietarse por aquellos jóvenes hispanos, que cada vez estaban más cerca y, por tanto, empezaban a ser valorados como unos rivales importantes.

Los Mundiales de 1974 tuvieron lugar en México. Aquella vez los piragüistas españoles se clasificaron para cinco finales, en lucha ya cerrada con todas las figuras mundiales. Nuestros palistas ya estaban presentes en todas las categorías: K-1, K-2 y K-4. La progresión seguía en aumento. El gran triunfo estaba ya muy cercano.

\section{Campeones del Mundo: alegría y decepción}

Los Mundiales de Belgrado, en 1975, marcaron sin duda el punto más elevado del piragüismo español. En la mitad de K-4, 1.000 metros, el barco español, formado por Herminio, Celorrio, Díaz-Flor y Misione, se proclamaba brillantemente 
campeón del mundo. Era el primer título mundial para el piragüismo español, conseguido además de forma clara y sin ninguna clase de dudas.

Este triunfo se producía el sábado, pero aquel claro triunfo les hizo ser conscientes de su superioridad por lo que empezaron a albergar muchas más esperanzas para el día siguiente pensando en la posibilidad de obtener tres medallas más, el 500 metros, K-1, el 4x500 metros, K-1 y el K-4, 10.000 metros ya que participaban en todas las pruebas.

En la mañana del domingo, por un fallo inexplicable del responsable del equipo español, Herminio no fue informado de la salida de su serie en el K-1, 500 metros, y al no presentarse a la salida fue eliminado, cuando había realizado previamente el mejor tiempo de todos los palistas. Después de varias gestiones, y con la ayuda del equipo rumano, se le permitió que tomase parte en las dos pruebas restantes, de las que también en principio se le quiso eliminar por la ausencia mencionada.

En el relevo 4 x 500 metros conseguían la medalla de bronce, que ya sabía a poco, a la vista del oro del día anterior. Herminio obtenía en su serie el mejor tiempo de todos los participantes, lo que ratificaba que su triunfo, en caso de haber podido tomar parte en el K-1, habría sido casi seguro.

Finalmente, para colmo de las desgracias de aquel día, en la final de 10.000 metros K-4, cuando marchaban los primeros, al doblar una ciaboga fueron alcanzados por la embarcación soviética, partiendo una pala. Como consecuencia de aquella circunstancia, fueron entonces superados por otras embarcaciones, llegando en aquellas condiciones a la meta en quinto lugar. En la llegada, decepción y llanto. De la alegría del sábado a la tristeza del domingo. Ello reflejaba, por otro lado, la confianza en sus posibilidades, al encontrarse tristes y decepcionados cuando acababan de lograr una medalla de oro y otra de bronce. Fueron sin duda aquellos Mundiales de Belgrado donde el piragüismo español brilló a mayor altura y quizás también el momento que Herminio recordaba como el más dulce a lo largo de su vida.

\section{Montreal, 76: La primera Medalla Olímpica}

En la edición de los Juegos canadienses se produjo el primer intento serio de boicotear los mismos, a cargo de los países africanos que, en un total de veinticuatro, ordenaron a sus deportistas regresar a sus lugares de origen. La razón esgrimida era la admisión de Nueva Zelanda, con el flojo argumento de que dicho país no debería ser admitido por haber permitido que un equipo de rugby disputase varios encuentros con equipos de Sudáfrica, nación que, como es sabido, se encontraba excluida del 
Comité Olímpico Internacional, a causa de la política racista que mantenía en aquellos años.

La celebración de los Juegos de Montreal tuvo lugar en el fragor de un debate político nacional que puso en riesgo su comienzo, y algunas fuentes bibliográficas posteriores afirman que aquellos Juegos estuvieron a punto de no celebrarse, como consecuencia de la fuerte oposición de algunos políticos que consideraban que no era lógico hipotecar el futuro económico de su país, por unos juegos deportivos. Gracias a la perseverancia y obstinación del entonces alcalde de Montreal, Jean Drapeau, los Juegos fueron una realidad para Montreal, aunque no es menos cierto que la deuda contraída por tal motivo no terminó de pagarse hasta el año 2000.

España presentó en piragüismo, para aquella edición al equipo del K-4, que en aquel momento era campeón del mundo, y que estaba integrado por José Celorrio, Ramón Misione, Herminio Menéndez y José Díaz-Flor.

Del recuerdo de Herminio rescatamos la circunstancia de que para aquellos Juegos de Montreal existía un exagerado optimismo con respecto a los resultados que podía conseguir la expedición española y prácticamente parecía exigirse a nuestros representantes el logro de conseguir una medalla. También reflexionaba con respecto a que aquella presión ambiental fue perjudicial, ya que suponía un exceso de responsabilidad para nuestros palistas que no podía dar buenos resultados. En las eliminatorias los españoles habían realizado el mejor tiempo y como consecuencia salieron como favoritos. La regata, como era de esperar, fue muy competida. Cuando se encontraban en la disputa de los últimos metros las posiciones igualadas hacían que fuera imposible vaticinar un vencedor. La embarcación española realizó un extraño en los momentos finales, aspecto que fue suficiente para que los soviéticos se colasen delante. Al final, el resultado obtenido fue la medalla de plata para el K4, 1.000 metros, que, como consecuencia de las expectativas no fue valorada con el calibre objetivo que realmente era. "No ganamos la plata"19 , dirían nuestros palistas, "perdimos el oro" 20 . Veintisiete centésimas de segundo tuvieron la culpa. En la prueba del K-1, 1.000 metros, se produjo otra llegada tremendamente igualada, con Herminio como representante español. Esta vez fue una décima de segundo, que colocaba a nuestra embarcación en el cuarto puesto. Al igual que en Yugoslavia, lo que en otra disciplina hubiese significado un gran triunfo para nuestros palistas, en racha de éxitos, fue considerado como una discreta actuación.

19 De entrevista mantenida por el autor con Herminio Menéndez Rodríguez, en Gijón (Asturias) en el mes de julio de 1989.

${ }^{20}$ Ibídem. 


\section{Los campeonatos mundiales}

El importante nivel conseguido ya en aquellos años por los piragüistas españoles puede ser medido por sus actuaciones y resultados en los Campeonatos Mundiales, en los que siempre estuvieron compitiendo por los primeros lugares. En 1977 el Mundial se celebró en Sofía. La selección sufrió la importante baja de Celorrio que fue sustituido por el juvenil Sánchez, que había conseguido la medalla de plata en el Mundial junior. Con el cuarteto formado por Herminio, Sánchez, DíazFlor y Misione, se lograron dos medallas de bronce, en 500 y 1.000 metros. En ambas pruebas los vencedores fueron los polacos, aunque no estaban entre los favoritos. Más tarde se descubrió que habían untado la embarcación con un producto que, posteriormente sería prohibido, consecuencia de que, al año siguiente, los polacos no obtuvieran ninguna medalla. Por tanto, se puede afirmar con justicia que la medalla de bronce conseguida por el equipo español en Sofía equivalía con objetividad a la medalla de plata.

La ciudad de Belgrado fue el escenario de los Mundiales de 1978. En aquella competición se produjo la vuelta de Celorrio al K-4, desplazando a Sánchez. Los resultados volvieron a ser extraordinarios consiguiendo otras dos medallas: Plata, en 500 metros y bronce, en 1.000 metros. Herminio consiguió otra vez el cuarto puesto en el K-1, 1.000 metros.

Los Mundiales de 1979 se disputaron en Duisburgo (Alemania). En aquella competición se produjeron algunos problemas con el K-4, que dieron como consecuencia unos resultados no esperados obteniendo el séptimo lugar en 1.000 metros y el cuarto en 500 metros. Aquello lo recordaba Herminio Rodríguez como una pequeña tragedia, como consecuencia de que ya todos los años se habían acostumbrado a conseguir medallas. El seleccionador decidió entonces que Herminio y Misione formasen el K-2, 10.000 metros. Ellos consiguieron una medalla de bronce, salvando de esta forma lo que de antemano parecía obligado: volver con alguna medalla.

\section{Los Juegos Olímpicos de Moscú de 1980: Dos nuevas medallas del piragüismo español}

Los Juegos de Moscú suponían una prueba de fuego para el piragüismo español, que se había situado durante varios años en la cresta de la ola. El exceso de competiciones, concentraciones, cansancio, etcétera, iba haciendo mella. Al no haber conseguido medalla en el K-4 de los últimos Mundiales, el seleccionador, Herrero, decidió que Herminio Rodríguez remara en las dos pruebas de K-2 y dejase la K-4. Ello originó una serie de problemas y, finalmente, Celorrio y Díaz-Flor, al no contar con la presencia de Herminio en la embarcación grande, decidieron abandonar. Aquello supuso que España se quedaba sin K-4, después de varios años de estar entre 
las mejores del mundo. Por otra parte, aquello también implicaba que parecía recaer una mayor responsabilidad sobre Herminio y que toda la atención parecía centrarse en él. Hizo el K-2, en 500 metros, con Del Riego y en 1.000 con Misione. La circunstancia del posible fracaso (y el no conseguir medalla ya era considerado un fracaso, tal como estaban las cosas) toda la responsabilidad parecería ser suya. ${ }^{21}$

Al final se consiguió la medalla de bronce en 1.000 metros y la medalla de plata en 500 metros. Dos nuevas medallas olímpicas que podían ya sumarse a los éxitos de este deportista asturiano de Candás. Las cosas quedaban claras. Desde el primer título mundial, en 1975, hasta Moscú 1980, Herminio había estado presente en todos los triunfos y medallas, tanto olímpicas como mundiales. Durante aquellos seis años ininterrumpidos, estuvo subiendo al podio de forma regular.

\section{Los Ángeles 1984: Despedida olímpica y decepción}

La edición de los Juegos de los Ángeles suponía para Herminio Menéndez Rodríguez su cuarta partición olímpica, este hecho ya suponía para un deportista español de aquellos años un hito importante que le situaba en un lugar destacado de la historia del olimpismo español. Entre sus reflexiones reconocía que él sabía que aquellos Juegos supondrían su última participación y albergaba la esperanza de poder despedirse con una medalla. ${ }^{22}$ Tenía a su favor el que, a causa del boicot soviético, los deportistas que a priori podrían ser sus rivales más fuertes estarían ausentes.

Sin embargo, aquella esperanza no pudo hacerse realidad. Las cosas no rodaron bien desde el primer momento, y varios aspectos cotidianos de su estancia y entrenamientos en Los Ángeles fueron difíciles. El lago se encontraba situado a casi 200 kilómetros de la villa olímpica. Este aspecto le obligaba a levantarse a las 4,30 horas de la mañana. Esta circunstancia ya le hacía estar en desventaja con otros competidores de otros países que habían establecido su campamento a pie del lago. Tuvo varios inconvenientes que se fueron superponiendo: desde problemas con el seleccionador, hasta una crema que debería facilitar la navegación, que para solucionarlo se terminó por usar otra que terminó haciendo el efecto contrario. El resultado de todo ello fue la sorpresa mayúscula de no pasar a la final en el K-2, 500 metros, haciendo pareja con Del Riego. La séptima plaza en la final de 1.000 metros fue recibida con frialdad, a la vista de las esperanzas que previamente habían albergado.

Las medallas olímpicas que, en teoría, estaban más fáciles, se esfumaron, sufriendo todo el conjunto español una gran decepción.

\footnotetext{
${ }^{21}$ Ibídem.

${ }^{22}$ Ibídem.
} 
La edición de los Juegos de Los Ángeles de 1984 significaba la retirada de Herminio Menéndez Rodríguez, tanto de los Juegos Olímpicos como del piragüismo de competición.

\section{El descenso del río Sella}

Para los piragüistas asturianos una victoria en el Descenso del Sella cobra si cabe mayor valor que los triunfos conseguidos en otras importantes regatas internacionales. Herminio no fue de los palistas que más prodigó sus actuaciones en esta prueba, ya que, generalmente, en las fechas veraniegas en las que suele tener lugar su celebración, se hallaba concentrado con el equipo nacional. Pero, a pesar de ello, es necesario recordar que cuenta en su haber con tres victorias. Dos veces en K2 (cuyo récord tuvo varios años, siendo batido, precisamente, en la edición del año 1988) y una victoria individual, en K-1. Tampoco es un balance desdeñable en el más internacional y popular descenso de río que hay en el mundo.

\section{Resumen del palmarés de Herminio Menéndez Rodríguez y otras circunstancias y conclusiones.}

\subsection{Resumen del palmarés}

Herminio Menéndez Rodríguez es:

Vencedor, entre otras, de las regatas internacionales de París, Londres, Nottingham, Moscú, Hungría, Rumanía, Duisburgo y México. del Mundo.

Ha conseguido tres medallas olímpicas y siete medallas en los Campeonatos

Formó parte del equipo español, fuera de nuestras fronteras, en más de sesenta ocasiones.

En nuestro país obtuvo más de cuarenta títulos nacionales.

Este mocetón de Candás, con 1,81 metros de estatura y 81 kilos de peso en sus buenos momentos, al abandonar la competición en 1984 estuvo durante dos años de director deportivo del Real Grupo de Cultura Covadonga, pasando más tarde a ser coordinador del programa olímpico Barcelona 92 . Posteriormente, fue nombrado asesor ejecutivo del secretario de Estado para el Deporte, Javier Gómez Navarro. Años después realizó labores de gestión en el Consejo Superior de Deportes. De vuelta a Asturias en Gijón se integró en el Real Sporting de Gijón, en donde fue Director General. 
El extraordinario palmarés que presenta es suficiente aval de la indiscutible categoría del más grande campeón de piragüismo que ha dado nuestro país, suponiendo ya una figura legendaria del deporte español.

\section{BIBLIOGRAFÍA Y FUENTES}

\section{Fuentes orales:}

Herminio Menéndez Rodríguez. Entrevistas realizada por el autor a en Gijón en junio y julio de 1989.

\section{Bibliografía}

Antuña Suárez, A. (1990): Asturias Olímpica. Historia de los olímpicos asturianos. Ed. Servicio de Publicaciones del Principado de Asturias.

Durántez Corral, C. (2006): Olimpismo para jóvenes. Ed. Fundación Educativa Sek. Madrid.

Mandell, R.D. (1986): Historia Cultural del Deporte. Ediciones Bellaterra. Barcelona.

Real Federación Española de Piragüismo (2009): "Crónica de medio siglo de piragüismo federado. Especial 50 aniversario, 19 de diciembre de 1959- 19 de diciembre de 2009". Consejo Superior de Deportes y Real Federación Española de Piraguiismo. 